\title{
Prevalence of Hypertension and Its Influencing Factors among Residents Aged 15-79 in Anyang City
}

\author{
Zhu Xiumin ${ }^{1}$, Duan $\mathrm{Fei}^{2}$,Liu Yanhua ${ }^{3}$, Chen $\mathrm{Wei}^{\mathbf{4}^{*}}$ \\ ${ }^{1,3}$ Community Nursing Teaching and Research Section, Henan Vocational College of Nursing, Anyang, \\ Henan, China \\ ${ }^{2}$ College of Stomatology Shanxi Medical University, Class 1,Grade 2019, Jinzhong,Shanxi, China \\ ${ }^{4}$ Anyang Center for Disease Control and Prevention, Anyang, Henan, China \\ *Corresponding Author
}

\begin{abstract}
Objective To understand the prevalence and influencing factors of hypertension among residents aged 15-79 years old in Anyang City, and to provide scientific basis for formulating intervention measures.Methods from October to November 2017, 6397 residents aged 15-79 years in Anyang City were selected by multistage stratified sampling method for questionnaire survey and physical examination.Results the prevalence rate of hypertension was $28.24 \%$, and the standardized rate was 28.38\%;Compared with different gender, age, education level, marital status, occupation, BMI, whether central obesity, daily salt intake, smoking, drinking, sleep and other factors, there were statistically significant differences in the prevalence of hypertension (all $P<0.001$ ), which increased with age and decreased with education level;The controllable risk factors of hypertension were overweight, central obesity, smoking, drinking, daily salt intake, sleep time, etc. the protective factors were college education level or above, knowing and answering correctly daily salt intake and standard sleep.Conclusion the prevalence rate of hypertension in Anyang residents aged 15-79 is high. Strengthening policy control, adopting the strategy of "whole population" and "high-risk population" to carry out health education and health promotion of hypertension prevention and control can effectively reduce the risk of hypertension and improve the compliance of standardized treatment and management of hypertension patients.
\end{abstract}

Keywords: hypertension;Prevalence rate; influence factor.

\section{Introduction}

Hypertension is one of the most common cardiovascular diseases seriously endangering human health and quality of life. It has high morbidity, mortality and disability, and is also an important risk factor for stroke, coronary heart disease and other cardiovascular and cerebrovascular diseases.Prevention and control of hypertension can significantly reduce the incidence and mortality of cardiovascular and cerebrovascular diseases, and improve the quality of life of patients [3] .Mastering the prevalence of hypertension and its influencing factors is the premise of effective prevention and control of hypertension.In order to implement the "healthy Anyang 2030" action plan of Anyang municipal government, this study carried out an epidemiological survey of hypertension among residents aged 15-79 in Anyang City from October to November 2017, and analyzed the influencing factors of hypertension, so as to provide reference for formulating appropriate prevention and control strategies.

\section{Object and Method}

2.1 Participants the subjects of this study were 15-79 years old permanent residents in Anyang City who lived in the survey area for more than 6 months.Linzhou city and Wenfeng District were randomly selected as rural and urban project counties (districts), and multi-stage sampling method was used for sampling.In the first stage, five townships (streets) were randomly selected according to the cluster sampling method proportional to the population size in the project counties (districts); In the second stage, two administrative villages (neighborhood committees) were randomly selected from each selected township (street) according to the cluster sampling method proportional to the population size; In the third stage, each selected administrative village (neighborhood committee) is divided into several villager / resident groups with no less than 90 households as the scale, and one villager / resident group is 
selected by simple random sampling method;In the fourth stage, at least 90 households were selected from each selected villager / resident group by cluster sampling.The sample size was 5056. Considering the situation of no response and waste paper, 6397 people were investigated, 5882 people were effectively investigated, and the effective rate was $91.95 \%$. All respondents signed informed consent.

2.2 Method

2.21Questionnaire investigation

The survey was carried out with the questionnaire developed by Anyang health and Family Planning Commission and Anyang Center for Disease Control and prevention.It was conducted by face-to-face inquiry by uniformly trained investigators. The contents include personal basic information, history of hypertension, family history, lifestyle and health care.

\subsection{Medical examination}

The height, weight, waist circumference and blood pressure were measured by unified trained physical examination personnel using unified specification tools and standard methods. The height was measured with a metal column altimeter with an accuracy of $0.1 \mathrm{~cm}$. The body weight was measured by electronic scale with an accuracy of $0.1 \mathrm{~kg}$. Waist circumference was measured with a waist ruler, accurate to $0.1 \mathrm{~cm}$. Blood pressure was measured by electronic sphygmomanometer [Omron] continuously for 3 times during sitting, with an interval of more than 1 min, and the mean value of 3 times was taken as the final measurement result.All measuring instruments meet the requirements of national metrology certification, and the measurement methods meet the requirements of the industrial standard of the people's Republic of China - human health monitoring anthropometry (WS / t424-2013).

\subsection{Diagnostic criteria}

Hypertension is defined as blood pressure measured three times on different days without using antihypertensive drugs, SBP $\geq 140 \mathrm{mmHg}$ and / or DBP $\geq 90 \mathrm{mmHg}$. Those who have a history of hypertension and are currently using antihypertensive drugs should still be diagnosed as hypertension, although their blood pressure is lower than 140 / $90 \mathrm{mmHg}$; The diagnostic criteria of overweight and obesity: Overweight refers to BMI of $24.0 \sim 27.9 \mathrm{~kg} / \mathrm{m} 2$, obesity refers to $\mathrm{BMI} \geq 28.0 \mathrm{~kg} / \mathrm{m} 2$ [4] ;Central obesity refers to male waist circumference $\geq 85 \mathrm{~cm}$ or female waist

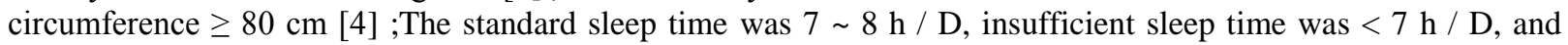
excessive sleep time was $>8 \mathrm{~h} / \mathrm{D}[5]]$.

\subsection{Statistical analysis}

Epidata3.1 was used for data entry and consistency test, SPSS 24.0 was used for data analysis, chi square test and logistic regression model were used to analyze the related risk factors of hypertension, and the test level was improved $\alpha=0.05$. The prevalence of hypertension was standardized according to the 2018 China Statistical Yearbook [6] ].

\section{III.Result}

\subsection{General information}

A total of 5882 residents aged 15-79 were investigated, including 2960 males (45.73\%) and 3192 females (54.27\%); There were 2915 urban residents (1315 males and 1600 females) and 2967 rural residents (1375 males and 1592 females).The average age was $43.46 \pm 26$ years old.

\subsection{Prevalence of hypertension in Anyang City (Table 1)}

The prevalence rate of hypertension was $28.24 \%$ (1661 / 5882) and the standardized rate was $28.38 \%(270393$ / 952893).Among them, the prevalence rate of hypertension in urban residents was $29.09 \%$ (848/2915), and the standardized rate was $30.26 \%$ (288324 / 952893), which was higher than that in rural residents $(27.40 \%$ (813 / 2967), and the standardized rate was $26.32 \%(250791 / 952893)(=2.071,>0.05)$ 。Compared with different gender, age, education level, marital status, occupation, body mass index (BMI), waist circumference, smoking, drinking and other factors, there were statistically significant differences in the prevalence of hypertension (all $<0.001$ ), and there was an upward trend with the increase of age and a downward trend with the increase of education level.Compared with different occupations, the highest prevalence rate of hypertension was $61.93 \%$ among retirees and the lowest 
was $1.91 \%$ among school students, while the prevalence rate of hypertension in business service industry $(13.16 \%)$ and professional and technical personnel $(14.91 \%)$ was lower than that in agriculture, forestry, animal husbandry and fishery production personnel $(31.55 \%)$ and production equipment operators $(35.81 \%)$. However, there was no significant difference in family history of hypertension $(>0.05) . P$ Daily salt intake $P P$

Table 1 prevalence of hypertension among residents aged 15-79 in Anyang City

\begin{tabular}{|c|c|c|c|c|c|}
\hline features & hypertension & $\begin{array}{l}\text { Non } \\
\text { hypertension }\end{array}$ & $\begin{array}{l}\text { Prevalence of } \\
\text { hypertension }(\%)\end{array}$ & $\chi t w o$ & $P$ \\
\hline urban and ruralcity & 848 & 2067 & 29.09 & 2.071 & 0.150 \\
\hline countryside & 813 & 2154 & 27.40 & & \\
\hline Gendermale & 895 & 1795 & 33.27 & 61.955 & 0.000 \\
\hline female & 766 & 2426 & 24.00 & & \\
\hline Age $<30$ & 100 & 1464 & 6.39 & 1119.898 & 0.000 \\
\hline $30 \sim$ & 418 & 1708 & 19.66 & & \\
\hline $50 \sim$ & 795 & 860 & 48.04 & & \\
\hline $70 \sim$ & 348 & 189 & 64.80 & & \\
\hline $\begin{array}{l}\text { degree of educationPrimary school and } \\
\text { below }\end{array}$ & 463 & 560 & 45.26 & 289.178 & 0.000 \\
\hline junior middle school & 719 & 1802 & 28.52 & & \\
\hline $\begin{array}{l}\text { High school / technical secondary school / } \\
\text { Technical School }\end{array}$ & 383 & 1042 & 26.88 & & \\
\hline College or bachelor degree or above & 96 & 817 & 10.51 & & \\
\hline marital statusunmarried & 53 & 827 & 6.02 & 340.418 & 0.000 \\
\hline Cohabitation or married & 1447 & 3270 & 30.68 & & \\
\hline Divorce, widowhood, separation & 161 & 124 & 56.49 & & \\
\hline $\begin{array}{l}\text { OccupationProduction personnel of } \\
\text { agriculture, forestry, animal husbandry } \\
\text { and fishery }\end{array}$ & 525 & 1139 & 31.55 & 586.575 & 0.000 \\
\hline Production equipment operators & 111 & 199 & 35.81 & & \\
\hline Business, service industry & 72 & 475 & 13.16 & & \\
\hline $\begin{array}{l}\text { Personnel of government organs, } \\
\text { enterprises and institutions }\end{array}$ & 60 & 191 & 23.90 & & \\
\hline Professional and technical personnel & 78 & 445 & 14.91 & & \\
\hline Other workers & 163 & 638 & 20.35 & & \\
\hline School Students & 6 & 308 & 1.91 & & \\
\hline Unemployed / domestic & 293 & 609 & 32.48 & & \\
\hline retirement & 353 & 217 & 61.93 & & \\
\hline BMI $<24$ & 579 & 2418 & 19.32 & 260.249 & 0.000 \\
\hline $24-28$ & 717 & 1327 & 35.08 & & \\
\hline$\geq 28$ & 365 & 476 & 43.40 & & \\
\hline Central obesityno & 476 & 2360 & 16.78 & 354.583 & 0.000 \\
\hline yes & 1185 & 1861 & 38.90 & & \\
\hline $\begin{array}{l}\text { Daily salt intakeKnow and answer } \\
\text { correctly }\end{array}$ & 336 & 1102 & 23.37 & 28.839 & 0.000 \\
\hline Knowing the wrong answer & 55 & 156 & 26.07 & & \\
\hline I don\&apos;t know & 1270 & 2963 & 30.00 & & \\
\hline Smoking statusSmoking every day & 293 & 651 & 31.04 & 98.759 & 0.000 \\
\hline Non daily smoking & 69 & 177 & 28.05 & & \\
\hline I used to smoke, but now I don\&apos;t & 154 & 140 & 52.38 & & \\
\hline Never & 1145 & 3253 & 26.03 & & \\
\hline $\begin{array}{l}\text { Drinking (last } 12 \text { months) } \\
\text { 30I\&apos; ve had wine in a few days }\end{array}$ & 341 & 648 & 34.48 & 23.4000 & 0.000 \\
\hline 30I had a drink two days ago & 137 & 345 & 28.42 & & \\
\hline Not yet & 1183 & 3228 & 26.82 & & \\
\hline Family historyyes & 862 & 2103 & 29.07 & 2.051 & 0.152 \\
\hline nothing & 799 & 2118 & 27.39 & & \\
\hline
\end{tabular}


3.3 Comparison of different characteristics of residents aged 15-79 with or without hypertension in Anyang City (Table 2) compared with non hypertensive residents, the age, BMI, waist circumference and daily smoking of residents aged 15-79 with hypertension were higher, while the sleep time was less, and the differences were statistically significant $(<0.01) . P$

Table 2 Comparison of different characteristics of hypertension among residents aged 15-79 in Anyang City

\begin{tabular}{|c|c|c|c|c|c|}
\hline hypertension & Age (years) & BMI(kg/m2) & $\begin{array}{l}\text { Waist } \\
\text { circumference } \\
(\mathrm{CM})\end{array}$ & $\begin{array}{l}\text { Smoking volume } \\
\text { (cigarettes / day) }\end{array}$ & $\begin{array}{l}\text { Sleep time } \\
\text { (hours / day) }\end{array}$ \\
\hline yes & $\begin{array}{l}56.25 \pm \text { ten } \\
\text { point nine } \\
\text { nine }\end{array}$ & $\begin{array}{l}\text { 25.52 } \pm \text { three } \\
\text { point six } \\
\text { four }\end{array}$ & $\begin{array}{l}86.81 \pm \text { eight } \\
\text { point seven } \\
\text { eight }\end{array}$ & $\begin{array}{l}3.02 \pm \text { seven point } \\
\text { one six }\end{array}$ & $\begin{array}{l}7.33 \pm \text { one point } \\
\text { four zero }\end{array}$ \\
\hline no & $\begin{array}{l}38.51 \pm \text { eleven } \\
\text { point seven } \\
\text { two }\end{array}$ & $\begin{array}{l}23.69 \pm \text { three } \\
\text { point five } \\
\text { three }\end{array}$ & $\begin{array}{l}80.91 \pm \text { eight } \\
\text { point nine five }\end{array}$ & $\begin{array}{l}2.40 \pm \text { six } \\
\text { one one }\end{array}$ & $\begin{array}{l}7.60 \pm \text { one point } \\
\text { two zero }\end{array}$ \\
\hline$t$ & 40.289 & 17.703 & 22.848 & 3.105 & -6.897 \\
\hline$P$ & 0.003 & 0.000 & 0.000 & 0.002 & 0.000 \\
\hline
\end{tabular}

3.4 Logistic regression analysis on the influencing factors of hypertension among 15-79 residents in Anyang City (Table 3) multivariate unconditional logistic regression analysis was conducted with the prevalence of hypertension among 15-79 years old residents in Anyang City as the dependent variable $(0=$ no, $1=$ yes $)$ and the factors with $\mathrm{P}<$ 0.05 in univariate analysis as the independent variable. The results showed that male, age $\geq 30$ years old, BMI 24 and above, central obesity, daily smoking, drinking more than 3 times a week, insufficient or too long sleep, and ignorance of daily salt intake were the risk factors for hypertension among residents aged 15-79 years old in Anyang City, while those with college education or above, knowing and answering correctly the daily salt intake, and having no knowledge of daily salt intake were the risk factors for hypertension among residents aged 15-79 years old in Anyang CityStandard sleep is a protective factor for hypertension among residents aged 15-79 in Anyang City.

Table 3 multivariate logistic regression analysis on Influencing Factors of hypertension among residents aged 15-79 in Anyang City, Henan Province

\begin{tabular}{|c|c|c|c|c|c|c|c|c|}
\hline factor & $\begin{array}{l}\text { Reference } \\
\text { group }\end{array}$ & B & $\begin{array}{l}\text { Standard } \\
\text { error }\end{array}$ & Wald & $\mathrm{P}$ & OR & $\begin{array}{l}\text { OR } \\
95 \% \mathrm{cc} \\
\text { interval }\end{array}$ & nfidence \\
\hline Genderfemale & male & -0.325 & 0.073 & 19.566 & 0.000 & 0.723 & 0.626 & 0.835 \\
\hline Age segment $30 \sim$ & $<30$ & 0.758 & 0.138 & 30.072 & 0.000 & 2.134 & 1.628 & 2.798 \\
\hline $50 \sim$ & & 1.861 & 0.143 & 170.041 & 0.000 & 6.433 & 4.863 & 8.510 \\
\hline $70 \sim$ & & 2.488 & 0.176 & 200.322 & 0.000 & 12.033 & 8.527 & 16.982 \\
\hline $\begin{array}{l}\text { MarriageCohabitation } \\
\text { or married }\end{array}$ & unmarried & 0.156 & 0.188 & 0.690 & 0.406 & 1.169 & 0.809 & 1.690 \\
\hline Separation, divorce, wide & owhood & 0.449 & 0.235 & 3.654 & 0.056 & 1.567 & 0.989 & 2.483 \\
\hline $\begin{array}{l}\text { Culturejunior middle } \\
\text { school }\end{array}$ & $\begin{array}{l}\text { Primary } \\
\text { school and } \\
\text { below }\end{array}$ & -0.022 & 0.095 & 0.054 & 0.817 & 0.978 & 0.812 & 1.179 \\
\hline $\begin{array}{l}\text { High school / technic } \\
\text { school / Technical Schoo }\end{array}$ & al secondary & 0.083 & 0.113 & 0.539 & 0.463 & 1.086 & 0.871 & 1.355 \\
\hline College or bachelor degr & ee or above & -0.494 & 0.165 & 9.017 & 0.003 & 0.610 & 0.442 & 0.842 \\
\hline $\begin{array}{l}\text { occupation } \\
\text { Production equipment } \\
\text { operators }\end{array}$ & $\begin{array}{l}\text { Production } \\
\text { personnel of } \\
\text { agriculture, } \\
\text { forestry, } \\
\text { animal } \\
\text { husbandry } \\
\text { and fishery }\end{array}$ & -0.103 & 0.159 & 0.423 & 0.515 & 0.902 & 0.661 & 1.231 \\
\hline Business, & & -0.681 & 0.174 & 15.253 & 0.000 & 0.506 & 0.359 & 0.712 \\
\hline
\end{tabular}


industry

Government organs, enterprises and institutions, administrative personnel

Professional and

technical personnel

Other workers

School Students

Unemployed /

domestic

$\begin{array}{lllllll}-0.280 & 0.202 & 1.919 & 0.166 & 0.756 & 0.509 & 1.123\end{array}$

$\begin{array}{lllllll}-0.381 & 0.169 & 5.068 & 0.024 & 0.683 & 0.490 & 0.952\end{array}$

$\begin{array}{lllllll}-0.536 & 0.147 & 13.331 & 0.000 & 0.585 & 0.439 & 0.780\end{array}$

$\begin{array}{lllllll}-1.341 & 0.452 & 8.804 & 0.003 & 0.262 & 0.108 & 0.634\end{array}$

retirement

$-0.058 \quad 0.109$

0.279

$0.598 \quad 0.944$

$0.762 \quad 1.169$

BMI 24

$0.083 \quad 0.152$

0.300

$0.584 \quad 1.087$

$0.807 \quad 1.463$

$0.383 \quad 0.083$

21.519

$0.000 \quad 1.467$

$1.248 \quad 1.724$

28

$0.729 \quad 0.107$

46.128

$0.000 \quad 2.072$

$1.679 \quad 2.558$

Central obesityyes no

$0.562 \quad 0.082$

46.716

$0.000 \quad 1.755$

$1.494 \quad 2.062$

Daily salt intakeKnow and answer correctly don\&apos;t know

$-0.240 \quad 0.083$

8.380

0.004

0.787

$0.669 \quad 0.925$

Knowing the wrong answer

SmokingSmoking Never

every day smoke

Non daily smoking

$-0.006 \quad 0.186$

0.001

0.975

0.994

$0.691 \quad 1.431$

$0.299 \quad 0.144$

4.319

0.038

1.349

1.017

1.788

$0.107 \quad 0.180$

0.357

0.550

1.113

$0.783 \quad 1.583$

I used to smoke, but now I don\&apos;

$0.122 \quad 0.169$

0.524

0.469

1.130

$0.811 \quad 1.574$

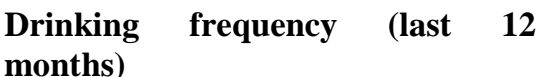
Less than 1 day / month per day

5-6Days / week

$0.715 \quad 0.199$

12.938

$0.000 \quad 2.044$

$1.385 \quad 3.018$

$0.707 \quad 0.232$

9.268

0.002

2.028

$1.286 \quad 3.196$

3-4Days / week

$0.549 \quad 0.216$

6.454

$0.011 \quad 1.731$

$1.134 \quad 2.643$

1-2Days / week

$0.047 \quad 0.137$

0.117

$0.732 \quad 1.048$

$0.801 \quad 1.371$

1-3Days / month

$0.295 \quad 0.169$

3.061

$0.080 \quad 1.344$

$0.965 \quad 1.871$

Sleep timeStandard

Non

sleep

standard

$-0.078 \quad 0.026$

9.006

0.003

0.925

0.879

0.973

\section{IV.Discuss}

The results showed that the prevalence rate of hypertension was $28.24 \%$, and the standardized rate was $28.38 \%$.It was higher than that in Henan Province (24.89\%, 15-74 years old, 2012), higher than that in China (27.8\%, 23.2\%, over 18 years old, 2015), higher than that in Xingtai City, Hebei Province (19.0\%, over 15 years old, 2013) [9] and Hainan Province (24.05\%, over 18 years old, 2017) [10] ] ,It was lower than the prevalence of hypertension in Hefei (35.3\%, over 15 years old, 2013) [11] and Shijingshan District (36.1\%, 2015) [12] ] , similar to that in Gansu Province $(27.73 \%, 2013)$ and Guizhou Province $(28.78 \%$, over 15 years old, 2015).It is suggested that the prevalence of hypertension in Anyang City is at a high level.[7] ] [8] ] [13] ] [14] ]

There was no significant difference in the prevalence of hypertension between urban and rural areas in Anyang City. The results were consistent with those in Hefei city and Xingtai City, suggesting that the gap between rural and urban areas was narrowing. ${ }^{[1][9]}$

Compared with different gender, age, education level, marital status, occupation, body mass index (BMI), waist circumference, daily salt intake, smoking, drinking and other factors, there were statistically significant differences in the prevalence of hypertension (all $<0.001$ ), and there was an upward trend with the increase of age and a downward trend with the increase of education level.Logistic regression analysis showed that male, age $\geq 30$ years old, BMI 24 and above, central obesity, daily smoking, drinking more than 3 times a week, insufficient or too long sleep, and unknown daily salt intake were risk factors for hypertension in Anyang residents aged 15-79 years old. College education and above were protective factors for hypertension in Anyang residents aged 15-79 years old,It is consistent with the research results of other provinces and cities, which may be related to the better self-care awareness of the people with college education or above, suggesting that health education is of great significance for the prevention and control of hypertension. $P^{[9-14]}$ 
Compared with different occupations, the highest prevalence rate of hypertension was $61.93 \%$ in retirees and the lowest was $1.91 \%$ in school students, which was mainly related to age.There was no significant difference in the prevalence rate of hypertension with or without family history $(>0.05)$, which was inconsistent with previous studies. It may be that people with family history of hypertension received relative attention in the publicity and education of hypertension prevention and control, and achieved good results in prevention and control.It is suggested that it is an important way to prevent and control the increase of the prevalence of hypertension to strengthen the publicity of hypertension related prevention and control knowledge for the whole population. $P^{[9-14]}$

Therefore, according to the survey on hypertension prevention and control work, the following suggestions are put forward: (1) it is still necessary to integrate hypertension prevention and control into the local medical and health service system and formulate corresponding policies, including team building, resource allocation, supervision and assessment, etc;2 The strategy of "whole population" and "high-risk group" was adopted to carry out health education on prevention and treatment of hypertension. The residents with risk factors of hypertension, especially those over 30 years old, with central obesity and bad habits such as smoking, drinking and high salt diet, were given health education and health promotion, To reduce the risk of hypertension, we should promote them to develop a good lifestyle and behavior habits, and carry out necessary interventions around salt reduction, oil control, weight control, smoking cessation and alcohol restriction;(3) At the same time, through regular physical examination, strengthen screening and other early detection, through regular follow-up and other ways to promote the self-management ability of patients with hypertension, advocate the compliance of standardized treatment and management, so as to effectively control hypertension.

\section{Acknowledgements}

This research was supported by Henan nursing vocational college nursing professional school enterprise co construction training base construction project (Project No. xm-02), approved by the Ministry of education "higher vocational education innovation and development action plan (2015-2018)" in April 2019.

\section{References}

[1] CHRYSANT S G, CHRYSANT G S.Effectiveness of lowering blood pres-sure to prevent stroke versus to prevent coronary events[J] .AmJ Cardiol, 2010, 106 (6): 825-829.

[2] Yan Li, Cao ye, Wang Qiushi, et al. Cox regression analysis on Influencing Factors of stroke in patients with hypertension [J] . China public health, 2016, 32 (6): 748 - 752

[3] Liu Lisheng. Chinese guidelines for prevention and treatment of hypertension 2010 [J] . Chinese Journal of hypertension, 2011, 19 (8): $701-743$

[4] Revision committee of guidelines for the prevention and treatment of hypertension in China, association of hypertension (China), Cardiovascular Society of Chinese Medical Association, hypertension Committee of Chinese Medical Association, et al. Guidelines for the prevention and treatment of hypertension in China (revised version in 2018) [J] . Chinese Journal of Cardiology, 2019, 24 (1): 24-56

[5] Guo Xiaofan, Zhang Xiaoyu, et al. Meta analysis of the relationship between sleep time and hypertension [J] . Chinese Journal of hypertension, 2013,21 (9): 748 - 754

[6] National Bureau of statistics of the people\&apos;s Republic of China. China Statistical Yearbook 2018 [M] . Beijing: China Statistics Press, 2018

[7] Zhou Gang, Wang congcongcong, Feng Shixian, et al. Epidemiological characteristics of hypertension among residents in Henan Province [J] . Journal of Zhengzhou University (Medical Edition), 2013, 48 (5): 671-674

[8] China Center for Disease Control and prevention. China chronic disease and its risk factors monitoring report (2013) [M] . Beijing: Military Medical Press, 2016: 25 - 63

[9] Chang Yongli. Epidemiological investigation on prevalence and influencing factors of hypertension among urban and rural residents in Xingtai City, Hebei Province [J]. Journal of practical cardio cerebrovascular diseases, 2015, 23 (11): 37-40

[10] Zhang Qin, Gong Xun, Wang Xuanxuan, et al. Hypertension status and influencing factors among 
residents in Hainan Province [J] . Public health and preventive medicine, 2018, 29 (6): 123-125

[11] Chen Juan, Xie Ji\&apos;an, ye Kui, et al. Investigation and Analysis on the prevalence of hypertension in urban and rural residents aged 15 and above in Hefei [J] . Chinese Journal of disease control, 2016, 20 (4): 366-369

[12] An Xinhua, Jiang Ying, Zhang Liang. Analysis on prevalence and influencing factors of hypertension among residents in Shijingshan District of Beijing [J] . China health education, 2017, 33 (9): 786-790

[13] Zhang Qi, Wang Dongdong, Liu Yidan, et al. Study on prevalence and influencing factors of hypertension in adults in Gansu Province [J] . Chinese Journal of general practice, 2019,22 (10): 1197-1202

[14] Liu Zhijun, Ou Fengying, Rao Wenbo, et al.Analysis on prevalence and influencing factors of hypertension among urban and rural residents in Guizhou Province [J] . China public health, online publication time: November 28, 2018 